\title{
Effects of microbial enzymes on starch and hemicellulose degradation in total mixed ration silages
}

\author{
Tingting Ning ${ }^{1}$, Huili Wang ${ }^{1}$, Mingli Zheng ${ }^{1}$, Dongze Niu', Sasa Zuo ${ }^{1}$, and Chuncheng $\mathrm{Xu}^{1}{ }^{1 \text { ** }}$
}

* Corresponding Author: Chuncheng Xu Tel: +86-10-62736480, Fax: +86-10-62737997,

E-mail: xucc@cau.edu.cn

'College of Engineering, China Agricultural University, Beijing 100083, China

Submitted Jan 18, 2016; Revised Mar 17, 2016; Accepted Apr 21, 2016
Objective: This study investigated the association of enzyme-producing microbes and their enzymes with starch and hemicellulose degradation during fermentation of total mixed ration (TMR) silage.

Methods: The TMRs were prepared with soybean curd residue, alfalfa hay (ATMR) or Leymus chinensis hay (LTMR), corn meal, soybean meal, vitamin-mineral supplements, and salt at a ratio of 25:40:30:4:0.5:0.5 on a dry matter basis. Laboratory-scale bag silos were randomly opened after $1,3,7,14,28$, and 56 days of ensiling and subjected to analyses of fermentation quality, carbohydrates loss, microbial amylase and hemicellulase activities, succession of dominant amylolytic or hemicellulolytic microbes, and their microbial and enzymatic properties.

Results: Both ATMR and LTMR silages were well preserved, with low $\mathrm{pH}$ and high lactic acid concentrations. In addition to the substantial loss of water soluble carbohydrates, loss of starch and hemicellulose was also observed in both TMR silages with prolonged ensiling. The microbial amylase activity remained detectable throughout the ensiling in both TMR silages, whereas the microbial hemicellulase activity progressively decreased until it was inactive at day 14 post-ensiling in both TMR silages. During the early stage of fermentation, the main amylase-producing microbes were Bacillus amyloliquefaciens (B. amyloliquefaciens), B. cereus, B. licheniformis, and B. subtilis in ATMR silage and B. flexus, B. licheniformis, and Paenibacillus xylanexedens (P. xylanexedens) in LTMR silage, whereas Enterococcus faecium was closely associated with starch hydrolysis at the later stage of fermentation in both TMR silages. B. amyloliquefaciens, B. licheniformis, and B. subtilis and B. licheniformis, B. pumilus, and P. xylanexedens were the main source of microbial hemicellulase during the early stage of fermentation in ATMR and LTMR silages, respectively.

Conclusion: The microbial amylase contributes to starch hydrolysis during the ensiling process in both TMR silages, whereas the microbial hemicellulase participates in the hemicellulose degradation only at the early stage of ensiling.

Keywords: Total Mixed Ration, Starch, Hemicellulose, Degradation, Microbial Enzymes

\section{INTRODUCTION}

Ensiling is complex process that involves the interaction among plant enzymes and the action of numerous microbial species, ultimately changing the biochemistry of silage [1]. Particular emphasis has been made in studies on the reactions involved in production of acids from water soluble carbohydrates (WSC) during ensiling [2], whereas the degradation of starch and structural carbohydrates did not receive the same interest. Some studies demonstrate that starch and hemicellulose degradation do take place during ensiling as their levels in pre-ensiled are higher than those after ensiling [3,4]. Furthermore, previous researches also indicate that they may also serve as substrates for acids production by microbes during ensiling $[5,6]$. It is expected that the degradation of starch and hemicellulose during ensiling 
could be a combined action of plant and microbial enzymes under the acidic conditions [3,7]; however, the mechanisms associated with starch and hemicellulose degradation during ensiling have not been fully elucidated.

In recent years, total mixed ration (TMR) silage has been widely applied to feeding dairy cows. There is an increasing practice to ensile moist and perishable agricultural and food by-products with dry feeds as TMR silage $[8,9]$. To date, however, little information is available about TMR silage, particularly regarding the extents and causes of starch and hemicellulose degradation in TMR silage during ensiling. To reveal the dynamics and mechanisms underlying the starch and hemicellulose loss with prolonged ensiling of TMR silage, TMR formulated mainly with soybean curd residue and two different roughages of alfalfa hay and Leymus chinensis hay were subjected to a series time of fermentation in this study. The loss of carbohydrates, microbial enzyme activities, succession of dominant amylolytic or hemicellulolytic microbes during ensiling as well as the microbial and enzymatic properties were investigated to clarify the main enzyme producing microbes and the roles of their enzymes in starch and hemicellulose degradation during fermentation of TMR silages.

\section{MATERIALS AND METHODS}

\section{Preparation of total mixed ration silages}

As shown in Table 1, soybean curd residue was mixed thoroughly with hays and other dry feeds to produce two types of TMR, TMR formulated with alfalfa hay (ATMR), and TMR formulated with Leymus chinensis (LTMR), respectively. The soybean curd residue was obtained from a local food factory in Beijing and used within the day of production. The two types of hay were chopped to a length of 1 to $2 \mathrm{~cm}$ prior to conducting the experiment. Approximately $200 \mathrm{~g}$ well-mixed TMR was placed into a plastic film bag (Hiryu KN type, $200 \times 300 \mathrm{~mm}$; Asahikasei, Tokyo, Japan) and the air was removed by sealing with an automatic vacuum sealer (R-320; Beijing Rishang Co., Beijing, China). A total 18 bags per treatment were stored in a room with temperature maintained between $27^{\circ} \mathrm{C}$ and $31^{\circ} \mathrm{C}$ and triplicate bags from each treatment were randomly opened after $1,3,7,14,28$, and 56 days of ensiling for laboratory analysis.

\section{Chemical analysis and microbial enumeration}

Non-fermented ATMR and LTMR samples were collected immediately after thorough mixing, and silage samples were collected at the time of silo opening. The dry matter (DM) content was determined by freeze drying and the DM losses were assessed by differences in weight and DM content. The crude protein $(\mathrm{CP})$ was analyzed according to the method 976.05 of the AOAC [10]. The acid detergent fiber (ADF) and neutral detergent fiber (aNDF) were measured using the method of Van Soest et al. [11]. Hemicellulose was estimated by subtracting the ADF value from the aNDF value. The WSC and starch contents were determined by the method described by Owens et al. [12]. To measure fermentation qualities, $10 \mathrm{~g}$ wet samples were homogenized with $90 \mathrm{~mL}$ sterilized distilled water at $4^{\circ} \mathrm{C}$, and then filtered through four layers of cheesecloth. The filtrates were used for determining $\mathrm{pH}$, ammonia nitrogen $\left(\mathrm{NH}_{3}-\mathrm{N}\right)$, and organic acids. The $\mathrm{pH}$ was measured using a glass electrode $\mathrm{pH}$ meter (S20K, Mettler Toledo, Greifensee, Switzerland), and the $\mathrm{NH}_{3}-\mathrm{N}$ content was measured according to the phenol-hypochlorite reaction method of Broderick and Kang [13]. The organic acids concentrations were determined by high performance liquid chromatography (LC-10A, SHIMADZE, Kyoto, Japan). The silage filtrates were centrifuged at $10,000 \times g$ for $5 \mathrm{~min}$ at $4^{\circ} \mathrm{C}$, passed through a $0.45 \mu \mathrm{m}$ filter under pressure, and then injected into the high performance liquid chromatography system. The analytical conditions were as follows: column, ShodexRspak KC-811S-DVB gel column $300 \times 8 \mathrm{~mm}$; oven temperature, $50^{\circ} \mathrm{C}$; mobile phase, $3 \mathrm{mmol}$ $\mathrm{HClO}_{4}, 1.0 \mathrm{~mL} / \mathrm{min}$; detector, SPD-M10AVP (SHIMADZE, Kyoto, Japan).

Populations of microorganisms were measured through the spread-plate count method. Lactic acid bacteria (LAB) were counted on de Man, Rogosa, and Sharpe (MRS) agar prepared using MRS broth (Difco, Detroit, MI, USA) with 1.6\% agar, after incubation in an anaerobic incubator at $37^{\circ} \mathrm{C}$ for $48 \mathrm{~h}$. Aerobic bacteria were determined on nutrient agar (Nissui,

Table 1. Ingredient proportions of TMRs and chemical composition of TMR ingredients

\begin{tabular}{|c|c|c|c|c|c|c|c|c|}
\hline \multirow{2}{*}{ Ingredients } & \multicolumn{2}{|c|}{ Proportion (g/kg DM) } & \multicolumn{6}{|c|}{ Chemical composition (g/kg DM) } \\
\hline & ATMR & LTMR & DM & $\mathrm{CP}$ & WSC & Starch & aNDF & ADF \\
\hline Soybean curd residue & 250 & 250 & 187 & 251 & 192 & 188 & 325 & 210 \\
\hline Alfalfa hay & 400 & - & 912 & 166 & 68 & 45 & 476 & 367 \\
\hline Leymus chinensis hay & - & 400 & 923 & 92 & 82 & 52 & 564 & 325 \\
\hline Corn meal & 300 & 300 & 892 & 89 & 114 & 750 & 105 & 32 \\
\hline Soybean meal & 40 & 40 & 898 & 430 & 30 & 70 & 132 & 96 \\
\hline $\mathrm{VMS}^{1)}$ & 5 & 5 & 908 & 125 & 120 & 580 & 150 & 63 \\
\hline Salt & 5 & 5 & - & - & - & - & - & - \\
\hline
\end{tabular}

TMR, total mixed ration; DM, dry matter; ATMR, total mixed ration prepared with alfalfa hay; LTMR, total mixed ration prepared with Leymus chinensis hay; CP, crude protein; WSC, water soluble carbohydrates; aNDF, neutral detergent fiber; ADF, acid detergent fiber; VMS, vitamin-mineral supplement.

1) VMS is a commercial product (Longde feed, Hebei, China) containing $12 \mathrm{~g} / \mathrm{kg} \mathrm{Zn,} 10 \mathrm{~g} / \mathrm{kg} \mathrm{Mn}, 5 \mathrm{~g} / \mathrm{kg} \mathrm{Fe}, 2 \mathrm{~g} / \mathrm{kg} \mathrm{Cu}$, a minimum of 5,000 IU of vitamin A/g, $600 \mathrm{IU}$ of vitamin D/g. 
Tokyo, Japan), whereas enterobacteria were enumerated on blue light broth (Nissui, Japan) with additional 1.6\% agar, after incubation at $30^{\circ} \mathrm{C}$ for $48 \mathrm{~h}$. Molds and yeasts were counted on potato dextrose agar (Nissui, Japan) incubated at $28^{\circ} \mathrm{C}$ for $72 \mathrm{~h}$, and yeasts were distinguished from molds by colony appearance and observation of cell morphology. The colonies were counted from the plates at appropriate dilutions, and the number was expressed as colony forming units (cfu) per gram of fresh matter (FM).

\section{Enzyme assays}

Wet samples ( $5 \mathrm{~g}$ ) were homogenized in $20 \mathrm{~mL}$ sterilized distilled water, and then filtered through cheesecloth and centrifuged at $10,000 \times \mathrm{g}$ for $5 \mathrm{~min}$ at $4^{\circ} \mathrm{C}$. The supernatants were used as crude enzyme extracts for measuring the microbial enzyme activity in ATMR and LTMR silages during ensiling. Total amylase activity was determined using the method described by Rosés and Guerra [14] with the following modifications: diluted crude enzyme extract was mixed with $0.1 \mathrm{M}$ citrate-phosphate buffer ( $\mathrm{pH}$ 6.0) and $1.0 \%$ soluble starch (previously maintained at $40^{\circ} \mathrm{C}$ for $5 \mathrm{~min}$ ) and determined the reducing sugars after 10 min of incubation at $40^{\circ} \mathrm{C}$ using the dinitrosalicylic acid (DNS) method [15]. One unit of amylase activity was defined as the amount of enzyme required to release $1 \mu \mathrm{g}$ of maltose equivalents per minute under the assay conditions Hemicellulase activity was determined by measuring the release of reducing sugar from the substrate $(1.0 \%$ xylan prepared with $0.1 \mathrm{M}$ acetate buffer, $\mathrm{pH} 6.0$ ) during the 60 min incubation at $40^{\circ} \mathrm{C}$. One unit of hemicellulase activity was defined as the amount of enzyme releasing $1 \mu \mathrm{g}$ of xylose equivalents per minute under the assay conditions [16].

\section{Screening and identification of enzyme-producing microorganisms}

The following procedure was employed to screen and isolate amylolytic or hemicellulolytic microorganisms from TMR silages during ensiling. To release the microorganisms in samples, $10 \mathrm{~g}$ wet samples were homogenized in $90 \mathrm{~mL}$ sterilized distilled water, and serially diluted from $10^{-1}$ to $10^{-5}$ in sterilized water. Each dilution $(50 \mu \mathrm{L})$ was evenly spread onto the modified nutrient agar and MRS agar to screen for enzyme-producing aerobic bacteria and LAB, respectively. The modified agar mediums were prepared according to the manufacturer's (Difco, USA) direction with the exception that beef extract and glucose were replaced with soluble starch or hemicellulose as the sole carbon source to screen for amylolytic or hemicellulolytic microorganisms, respectively [17]. After cultivation under recommended conditions, strains with a clear halo around the colony were isolated and purified by repeated streaking and checked for homogeneous morphology. The purified isolates were conserved in $20 \%$ glycerol at $-80^{\circ} \mathrm{C}$ for further analysis.

To identify the species of the purified isolates, polymerase chain reaction (PCR) was carried out to amplify the complete $16 \mathrm{~S}$ rRNA gene sequence with the forward primer $27 f\left(5^{\prime}\right.$-AG AGTTTGATCCTGGCTCAG- $3^{\prime}$ ) and the reverse primer $1492 \mathrm{r}$ (5'-GGTTACCTTGTTACGACTT-3') [18]. The PCR procedure was performed as described by Hu et al. [9]. The PCR products were separated by gel electrophoresis on a $1.0 \%$ agarose gel, detected by Gold View (Solarbio, Beijing, China) according to the manufacturer's instructions and photographed under UV light with a charge-coupled device camera. Sequencing was carried out by Shanghai Sunny Biotechnology Co., Ltd. (Shanghai, China), and then the sequences were analyzed using BLASTN online tool (http:/blast.ncbi.nlm.nih.gov/ Blast.cgi). The 16S rRNA gene sequences of isolates and sequences from the type strains held in GenBank were aligned with program CLUSTAL W [19]. Phylogenetic tree was constructed from the evolutionary distance data that were calculated from Kimura's two-parameter model [20] using the neighbor-joining method [21]. Bootstrap analyses were performed on 1,000 random resamplings. Evolutionary analyses were conducted in MEGA6 [22]. The nucleotide sequences for the 16S rRNA gene described in this paper were deposited in the NCBI GenBank data library under accession numbers KU239970 to KU239983.

\section{Analysis of microbial and enzymatic properties}

The pure cultures were cultivated at proper temperature $\left(30^{\circ} \mathrm{C}\right.$ and $37^{\circ} \mathrm{C}$ for aerobic bacteria and $\mathrm{LAB}$, respectively) for $24 \mathrm{~h}$ and then inoculated into liquid fermentation mediums. After $48 \mathrm{~h}$ of cultivation at their corresponding temperatures with shaking at $160 \mathrm{rpm}$, the effects of $\mathrm{pH}$ on the enzyme activity in the supernatant was determined using the method as described above and buffers with $\mathrm{pH}$ in the range between 4.0 and 7.0. Survival and growth of pure cultures under anaerobic conditions were performed using the method described by Liu et al. [23]. Growth of purified aerobic bacteria and LAB was assessed at $\mathrm{pH}$ from 4.0 to 7.0 in nutrient broth (Difco, USA) and MRS broth after incubation at $30^{\circ} \mathrm{C}$ and $37^{\circ} \mathrm{C}$ for $3 \mathrm{~d}$, respectively.

\section{Statistical analysis}

Statistical analysis was performed using the general linear model procedure of IBM SPSS Statistics for Windows (Version 20.0; IBM Co., Armonk, NY, USA). Data on fermentation qualities, microbial counts, chemical compositions, ensiling losses and microbial enzyme activities were subjected to twoway analysis of variance, with the fixed effects of days of ensiling, type of TMR (ATMR vs LTMR), and the interactions between days of ensiling and type of TMR. Significance was defined at a 0.05 probability level.

\section{RESULTS}

Fermentation quality and microbial components during 
Table 2. Changes in fermentation quality and microbial components during ensiling of ATMR and LTMR silages

\begin{tabular}{|c|c|c|c|c|c|c|c|c|c|c|c|c|c|c|c|c|c|c|}
\hline \multirow{2}{*}{ Parameters } & \multicolumn{7}{|c|}{ ATMR } & \multicolumn{7}{|c|}{ LTMR } & \multirow{2}{*}{ SEM } & \multicolumn{3}{|c|}{ p-value ${ }^{1)}$} \\
\hline & 0 & 1 & 3 & 7 & 14 & 28 & 56 & 0 & 1 & 3 & 7 & 14 & 28 & 56 & & D & $T$ & $\mathrm{D} \times \mathrm{T}$ \\
\hline \multicolumn{19}{|l|}{ Fermentation quality } \\
\hline $\mathrm{pH}$ & 5.89 & 4.86 & 4.82 & 4.44 & 4.15 & 4.14 & 4.06 & 6.39 & 5.14 & 5.07 & 4.40 & 4.16 & 4.05 & 4.03 & 0.11 & $* *$ & ** & ** \\
\hline Lactic acid (g/kg DM) & 7.04 & 44.4 & 49.0 & 58.7 & 66.1 & 68.5 & 71.9 & 5.27 & 38.7 & 47.2 & 60.7 & 68.4 & 72.5 & 75.6 & 3.42 & $* *$ & * & ** \\
\hline Acetic acid (g/kg DM) & 2.43 & 5.96 & 6.32 & 7.49 & 8.98 & 9.19 & 10.1 & 1.92 & 5.05 & 5.82 & 7.10 & 8.07 & 8.47 & 8.96 & 0.37 & $* *$ & ** & NS \\
\hline $\mathrm{NH}_{3}-\mathrm{N}(\mathrm{g} / \mathrm{kg} \mathrm{TN})$ & 3.60 & 10.2 & 14.1 & 21.1 & 25.0 & 30.3 & 36.4 & 3.28 & 13.0 & 16.0 & 19.1 & 22.7 & 28.7 & 31.7 & 1.55 & ** & * & ** \\
\hline \multicolumn{19}{|c|}{ Microbial components ( $\left.\log _{10} \mathrm{cfu} / \mathrm{g} F \mathrm{FM}\right)$} \\
\hline$L A B$ & 6.62 & 8.52 & 8.65 & 8.33 & 8.30 & 7.83 & 7.12 & 6.68 & 8.79 & 8.87 & 9.00 & 8.59 & 8.24 & 7.05 & 0.13 & ** & ** & * \\
\hline Aerobic bacteria & 6.44 & 6.09 & 5.11 & 4.71 & 4.35 & 4.18 & 4.15 & 6.80 & 6.18 & 5.58 & 5.02 & 4.41 & 4.24 & 4.32 & 0.14 & ** & ** & * \\
\hline Enterobacteria & 5.79 & 4.61 & 3.20 & $N D^{21}$ & ND & ND & ND & 5.68 & 5.09 & 3.00 & ND & ND & ND & ND & 0.20 & $* *$ & NS & * \\
\hline Yeasts & 5.74 & 4.54 & 3.84 & 3.18 & ND & ND & $N D$ & 5.88 & 4.76 & 3.93 & 3.24 & ND & $N D$ & $N D$ & 0.19 & $* *$ & ** & ** \\
\hline Molds & $N D$ & $N D$ & ND & ND & ND & ND & $N D$ & $N D$ & ND & ND & ND & ND & $N D$ & $N D$ & - & - & - & - \\
\hline
\end{tabular}

ATMR, total mixed ration prepared with alfalfa hay; LTMR, total mixed ration prepared with Leymus chinensis hay; SEM, standard error of mean; DM, dry matter; NS, not significant; $\mathrm{NH}_{3}-\mathrm{N}$, ammonia-N; $\mathrm{TN}$, total nitrogen; FM, fresh matter; $L A B$, lactic acid bacteria.

Data are presented as means of three replicates.

${ }^{1)} D$, effect of days of ensiling; $T$, effect of type of TMR; $D \times T$, interaction between days of ensiling and type of TMR. ${ }^{* *} p<0.001$; * $p<0.05$.

${ }^{2)} \mathrm{ND}$, not detected. Microbial counts below the detection level is assigned a value corresponding to half of the detection limit $\left(2.40\right.$, i.e., $\log _{10} 250$ cfu/g), numerically for statistical analysis.

\section{ensiling}

Both ATMR and LTMR silages were well preserved, with low $\mathrm{pH}$ and $\mathrm{NH}_{3}-\mathrm{N}$ concentration, and high concentration of lactic acid (Table 2). The days of ensiling influenced $(\mathrm{p}<0.05)$ all the fermentation characteristics and microbial parameters, whereas the type of TMR affected ( $\mathrm{p}<0.05)$ most of the studied parameters except the enterobacteria population. The interaction between days of ensiling and type of TMR significantly affected $(\mathrm{p}<0.05) \mathrm{pH}$, lactic acid and $\mathrm{NH}_{3}-\mathrm{N}$ concentrations, and microbial parameters. The $\mathrm{pH}$ of the non-fermented ATMR and LTMR was 5.89 and 6.39, respectively, and it was reduced to below 4.2 after $14 \mathrm{~d}$ of fermentation. Concentrations of lactic and acetic acids increased throughout the ensiling period. Changes in $\mathrm{NH}_{3}-\mathrm{N}$ concentration during ensiling showed a similar trend to that observed for acids; it increased as the ensiling process progressed in both TMR silages. The epiphytic LAB populations in both TMRs were above $10^{6} \mathrm{cfu} / \mathrm{g} \mathrm{FM}$, and peaking to $10^{8} \mathrm{cfu} / \mathrm{g}$ FM at day 3 post-ensiling for ATMR silage and $10^{9} \mathrm{cfu} / \mathrm{g} \mathrm{FM}$ at day 7 post-ensiling for LTMR silage. The number of aerobic bacteria in both TMR silages declined gradually during the ensiling process and remained at $10^{4} \mathrm{cfu} / \mathrm{g}$ FM after $56 \mathrm{~d}$ of fermentation, whereas the enterobacteria were below detectable levels after $7 \mathrm{~d}$ of fermentation in both TMR silages. Yeasts population decreased as ensiling advanced and became undetected after $14 \mathrm{~d}$ of ensiling, while no molds were detected throughout the ensiling periods in both TMR silages.

\section{Chemical composition and losses during ensiling}

The initial WSC and starch content of ATMR were similar to the values observed in LTMR, whereas the initial hemicellulose content was higher in LTMR than in ATMR (Table 3). Significant decline $(\mathrm{p}<0.05)$ was detected in chemical components, with the exception of the $\mathrm{CP}$ content, which showed an increase $(\mathrm{p}<0.05)$ during ensiling in both TMR silages. The aNDF and ADF contents showed significant interaction $(\mathrm{p}<0.05)$ between days of ensiling and type of TMR. The DM and carbohydrates losses were affected $(\mathrm{p}<0.05)$ by both the days of

Table 3. Changes in chemical composition during ensiling of ATMR and LTMR silages

\begin{tabular}{|c|c|c|c|c|c|c|c|c|c|c|c|c|c|c|c|c|c|c|}
\hline \multirow{2}{*}{ Parameters } & \multicolumn{7}{|c|}{ ATMR } & \multicolumn{7}{|c|}{ LTMR } & \multirow{2}{*}{ SEM } & \multicolumn{3}{|c|}{ p-value ${ }^{1)}$} \\
\hline & 0 & 1 & 3 & 7 & 14 & 28 & 56 & 0 & 1 & 3 & 7 & 14 & 28 & 56 & & D & $\mathbf{T}$ & $\mathrm{D} \times \mathrm{T}$ \\
\hline $\mathrm{DM}$ (g/kg FM) & 462 & 460 & 459 & 457 & 456 & 455 & 453 & 449 & 448 & 448 & 446 & 445 & 443 & 442 & 1.05 & $* *$ & $* *$ & NS \\
\hline CP (g/kg DM) & 174 & 173 & 173 & 174 & 175 & 176 & 178 & 143 & 143 & 144 & 144 & 146 & 146 & 148 & 2.33 & $* *$ & ** & NS \\
\hline WSC (g/kg DM) & 111 & 72.2 & 66.3 & 57.3 & 52.1 & 50.8 & 49.3 & 117 & 81.4 & 72.2 & 63.2 & 60.5 & 57.6 & 55.8 & 2.86 & $* *$ & $* *$ & NS \\
\hline Starch (g/kg DM) & 296 & 258 & 251 & 247 & 245 & 244 & 244 & 298 & 274 & 264 & 261 & 258 & 257 & 256 & 2.68 & $* *$ & $* *$ & NS \\
\hline aNDF (g/kg DM) & 309 & 303 & 296 & 293 & 290 & 287 & 285 & 344 & 334 & 323 & 315 & 307 & 302 & 295 & 2.73 & $* *$ & $* *$ & * \\
\hline ADF (g/kg DM) & 213 & 210 & 208 & 206 & 205 & 205 & 206 & 196 & 194 & 188 & 184 & 182 & 180 & 178 & 1.88 & $* *$ & ** & * \\
\hline Hemicellulose (g/kg DM) & 95.2 & 92.5 & 88.5 & 86.6 & 84.7 & 82.2 & 79.2 & 148 & 140 & 135 & 130 & 125 & 122 & 117 & 3.75 & $* *$ & ** & NS \\
\hline
\end{tabular}

ATMR, total mixed ration prepared with alfalfa hay; LTMR, total mixed ration prepared with Leymus chinensis hay; SEM, standard error of mean; DM, dry matter; FM, fresh matter; NS, not significant; CP, crude protein; WSC, water soluble carbohydrates; aNDF, neutral detergent fiber; ADF, acid detergent fiber.

Data are presented as means of three replicates.

${ }^{1)} D$, effect of days of ensiling; $T$, effect of type of TMR; $D \times T$, interaction between days of ensiling and type of TMR; ${ }^{* *} p<0.001$; ${ }^{*} p<0.05$. 
Table 4. Losses of dry matter and carbohydrates during ensiling of ATMR and LTMR silages

\begin{tabular}{|c|c|c|c|c|c|c|c|c|c|c|c|c|c|c|c|c|}
\hline \multirow{2}{*}{ Parameters } & \multicolumn{6}{|c|}{ ATMR } & \multicolumn{6}{|c|}{ LTMR } & \multirow{2}{*}{ SEM } & \multicolumn{3}{|c|}{$p$-value ${ }^{1)}$} \\
\hline & 1 & 3 & 7 & 14 & 28 & 56 & 1 & 3 & 7 & 14 & 28 & 56 & & D & $\mathrm{T}$ & $\mathrm{D} \times \mathrm{T}$ \\
\hline DM (\%) & 0.50 & 0.88 & 1.29 & 1.88 & 2.59 & 3.70 & 0.29 & 0.42 & 1.05 & 1.71 & 2.49 & 3.39 & 0.19 & ** & ** & NS \\
\hline WSC (\%) & 35.5 & 40.8 & 49.1 & 54.0 & 55.5 & 57.3 & 30.4 & 38.3 & 46.3 & 48.9 & 51.8 & 53.7 & 1.46 & ** & ** & NS \\
\hline Starch (\%) & 13.2 & 15.9 & 17.8 & 18.6 & 19.5 & 20.5 & 8.18 & 11.7 & 13.2 & 14.8 & 16.0 & 17.1 & 0.62 & ** & ** & NS \\
\hline Hemicellulose (\%) & 3.35 & 7.86 & 10.1 & 12.7 & 15.9 & 19.9 & 5.38 & 8.82 & 12.6 & 16.7 & 19.2 & 23.5 & 1.02 & ** & ** & NS \\
\hline
\end{tabular}

ATMR, total mixed ration prepared with alfalfa hay; LTMR, total mixed ration prepared with Leymus chinensis hay; SEM, standard error of mean; DM, dry matter; NS, not significant; WSC, water soluble carbohydrates.

Data are presented as means of three replicates.

${ }^{1)} D$, effect of days of ensiling; $T$, effect of type of TMR; $D \times T$, interaction between days of ensiling and type of TMR; ** $p<0.001$.

ensiling and type of TMR (Table 4). The DM losses gradually increased as the ensiling advanced and appeared highest after $56 \mathrm{~d}$ of ensiling in both TMR silages. Approximately $57 \%$ and $54 \%$ of WSC were lost in ATMR and LTMR silages, respectively, after $56 \mathrm{~d}$ of ensiling, and the greatest quantity was lost during the first day of fermentation. The starch and hemicellulose losses for both TMR silages also increased with prolonged ensiling time. Higher losses of DM, WSC, and starch, but lower hemicellulose losses were obtained in ATMR silage compared to LTMR silage during the same ensiling period.

\section{Microbial amylase and hemicellulase activities during ensiling}

Dynamic changes in microbial amylase and hemicellulase activities in ATMR and LTMR silages during ensiling are shown in Figure 1. The microbial amylase activity declined rapidly $(\mathrm{p}<0.05)$ during the initial $7 \mathrm{~d}$ of fermentation in both TMR silages. It remained at $25 \%$ and $43 \%$ of its original amylase activity in ATMR and LTMR silages, respectively, after $56 \mathrm{~d}$ of fermentation, whereas the hemicellulase activity progressively decreased until it was inactive at day 14 post-ensiling in both TMR silages. Compared between the two TMR silages, higher

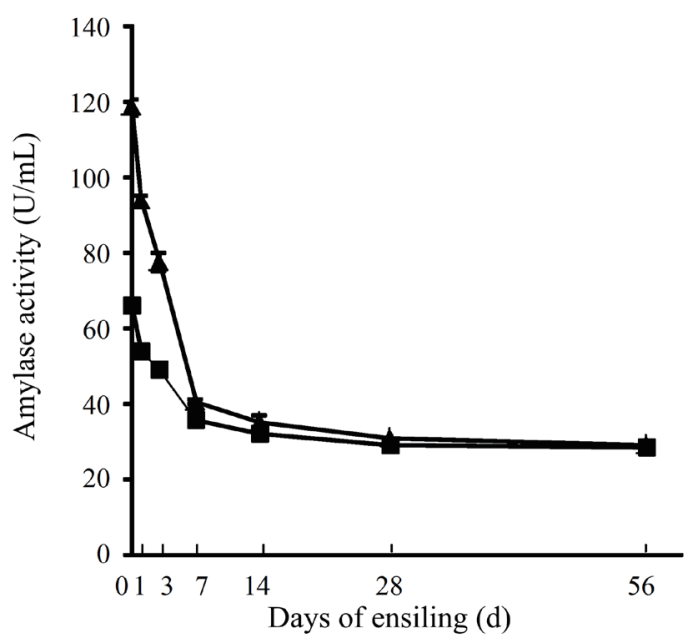

$(p<0.05)$ amylase activity but lower $(p<0.05)$ hemicellulose activity was observed in ATMR silages.

\section{Isolation, identification, and characterization of} amylolytic and hemicellulolytic microbes during ensiling A total of 62 and 80 enzyme-producing strains were isolated from ATMR and LTMR silages, respectively. The isolates were identified as eight species, showing more than $99 \%$ similarity in the 16S rRNA gene sequences with each corresponding type strains (Table 5). In total, five strain groups (A1 to A5) were isolated from ATMR (silages) and five strain groups (L1 to L5) from LTMR (silages). As shown in Table 5 and Figure 2, strain groups A1, A3/L2, A4, and L4 were placed in clusters of Bacillus amyloliquefaciens (B. amyloliquefaciens), B. licheniformis, B. subtilis, and Paenibacillus xylanexedens (P. xylanexedens), respectively, having both amylase and hemicellulase activity. Strain groups A2, L1, and A5/L5 were placed in clusters of $B$. cereus, B. flexus, and Enterococcus faecium (E. faecium), respectively, producing only amylase. Strain group L3 was clearly assigned to the specie $B$. pumilus, having hemicellulase activity alone. Strain groups A1, A2, L1, A3/L2, L3, A4, and L4 were detectable throughout the ensiling periods, whereas strain

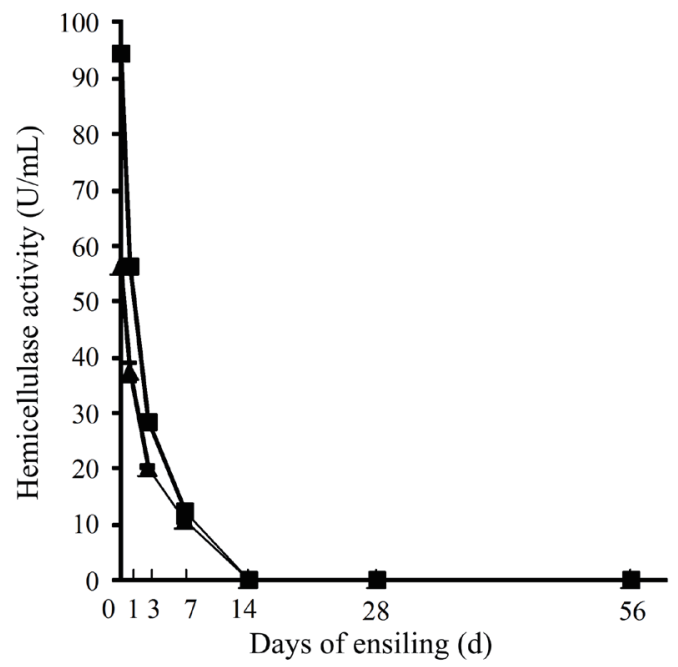

Figure 1. Changes in microbial amylase and hemicellulase activities during ensiling of ATMR $(\bullet)$ and LTMR ( $\mathbf{\square})$ silages. ATMR, total mixed ration prepared with alfalfa hay; LTMR, total mixed ration prepared with Leymus chinensis hay. 
Table 5. Amylolytic and hemicellulolytic microbes isolated from ATMR and LTMR silages

\begin{tabular}{|c|c|c|c|c|c|c|c|c|c|c|}
\hline \multirow{2}{*}{ Group $^{1), 2)}$} & \multirow{2}{*}{ Type strain (accession no.) } & \multirow{2}{*}{$\begin{array}{c}\text { Similarity } \\
(\%)\end{array}$} & \multirow{2}{*}{ Amylase $^{3)}$} & \multirow{2}{*}{ Hemicellulase $^{4)}$} & \multicolumn{2}{|c|}{ Growth in $^{5)}$} & \multicolumn{4}{|c|}{ Growth at $\mathrm{pH}^{6)}$} \\
\hline & & & & & Aerobic & Anaerobic & 4.0 & 4.5 & 5.0 & 7.0 \\
\hline A1 & Bacillus amyloliquefaciens NBRC 15535T (AB255669) & $99.8-99.9$ & + & + & + & + & - & w & + & + \\
\hline $\mathrm{A} 2$ & Bacillus cereus NBRC 15305T (AB271745) & $99.9-100$ & + & - & + & + & - & w & + & + \\
\hline L1 & Bacillus flexus NBRC 15715T (AB680944) & 99.8 & + & - & + & - & - & w & + & + \\
\hline $\mathrm{A} 3 / \mathrm{L} 2$ & Bacillus licheniformis NBRC 12200T (AB680255) & $99.4-99.8$ & + & + & + & + & - & - & + & + \\
\hline L3 & Bacillus pumilus NBRC 12092T (AB271753) & 99.9 & - & + & + & - & - & - & + & + \\
\hline A4 & Bacillus subtilis DSM 10T (AJ276351) & $99.9-100$ & + & + & + & - & - & w & + & + \\
\hline L4 & Paenibacillus xylanexedens B22aT (EU558281) & 99.7 & + & + & + & + & - & w & + & + \\
\hline A5/L5 & Entrococcus faecium ATCC 19434T (DQ411813) & $99.8-99.9$ & + & - & + & + & + & + & + & + \\
\hline
\end{tabular}

ATMR, total mixed ration prepared with alfalfa hay; LTMR, total mixed ration prepared with Leymus chinensis hay.

${ }^{1)}$ Groups A1-A5 were isolated from ATMR (silages) and Groups L1-L5 were isolated from LTMR (silages).

${ }^{2)}$ Groups A1-A4 and L1-L4 were detectable throughout the ensiling periods, whereas group A5/L5 was detected starting from day 7 post-ensiling until day 56 post-ensiling of fermentation.

${ }^{3), 4)}+$, positive; -, negative; ${ }^{5), 6)}+$, normal growth; w, weak growth; -, no growth.

group A5/L5 was detected starting from day 7 post-ensiling until day 56 post-ensiling of fermentation. All the strain groups grew in aerobic conditions, and most of the strain groups, except for groups L1, L3, and A4, grew in anaerobic conditions

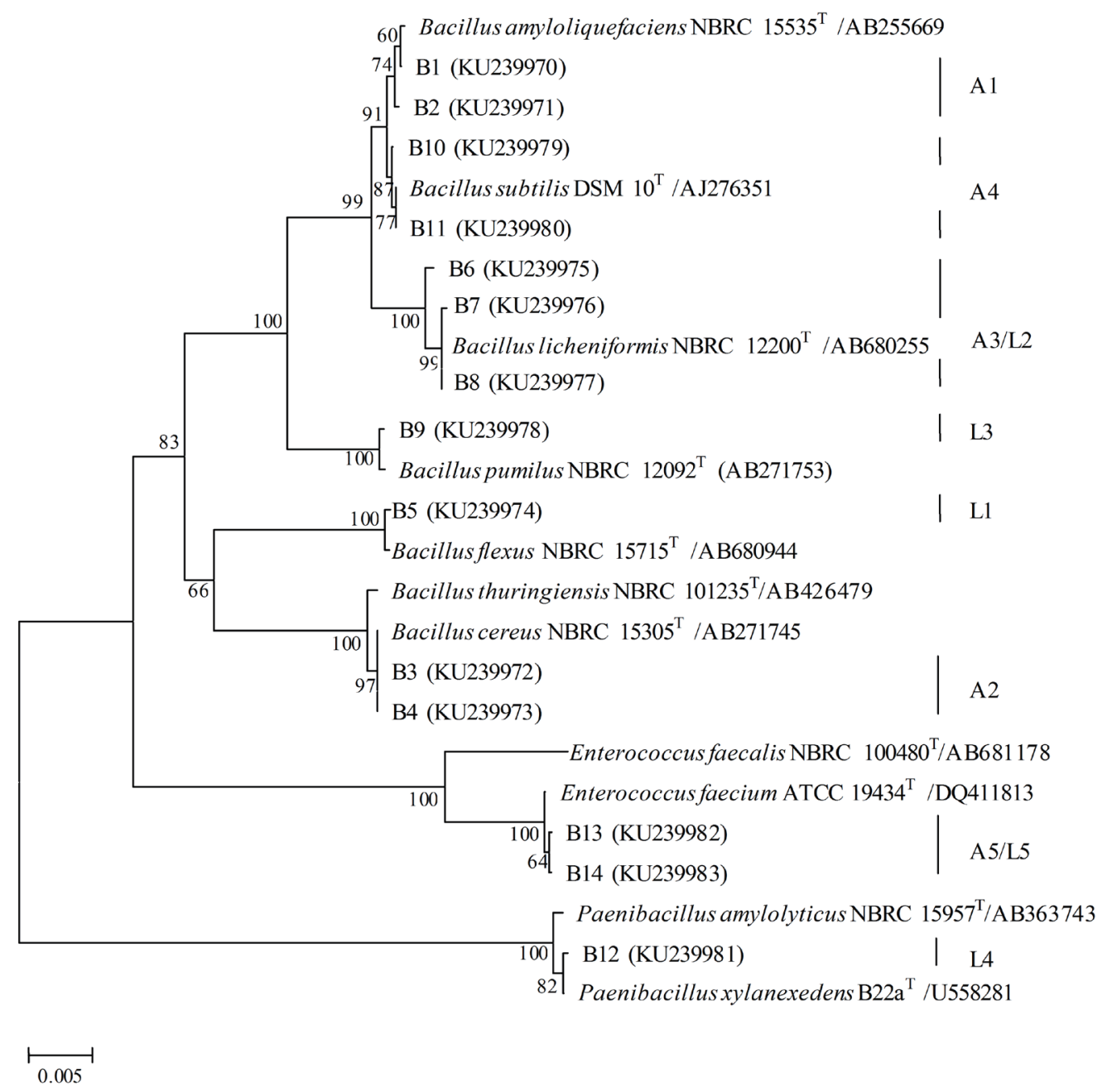

Figure 2. Phylogenetic tree showing the relative positions of isolated enzyme-producing strains and related species as inferred by the neighbor-joining method of complete 165 rRNA gene sequence. Bootstrap values for a total of 1,000 replicates are shown at the nodes of the tree. The bar indicates $0.5 \%$ sequence divergence. The GenBank accession no. of each type strain 165 rRNA gene is shown behind the type strain. 
as well. Stain groups $\mathrm{A} 3 / \mathrm{L} 2$ and $\mathrm{L} 3$ did not grow at $\mathrm{pH} 4.5$ and $\mathrm{A} 1, \mathrm{~A} 2, \mathrm{~L} 1, \mathrm{~A} 4$, and L4 grew weakly at this $\mathrm{pH}$. Strain group A5/L5 grew well at $\mathrm{pH} 4.0$ and others did not.

The effects of $\mathrm{pH}$ on the amylase and hemicellulase activities of microbes isolated from ATMR and LTMR silages during ensiling are shown in Table 6. The amylase activities of strain groups A2, L1, A3/L2, A4, and L4 were optimal at $\mathrm{pH} 6.0$, and more than $62 \%$ of their activity was retained between $\mathrm{pH} 5.0$ and 7.0; the exception was strain group L1, which amylase activity declined sharply as $\mathrm{pH}$ below 6.0. The amylase produced by strain groups $\mathrm{A} 1$ and A5/L5 presented maximum activity at $\mathrm{pH} 7.0$ and 5.0, respectively, and retained more than $56 \%$ of their activity within the $\mathrm{pH}$ range of 4.0 to 7.0. The optimum $\mathrm{pH}$ value for hemicellulase activity in all hemicellulolytic strain groups was 6.0. These strain groups maintained more than $54 \%$ of their hemicellulase activity at $\mathrm{pH}$ between 5.0 and 7.0, with the exception of strain group L3, which hemicellulase activity substantially decreased at $\mathrm{pH}$ below 6.0. Moreover, strain groups A1, A3/L2, and A4 displayed relatively higher amylase activities compared to other amylolytic strain groups, and strain group L3 showed the highest hemicellulase activity among the hemicellulolytic strain groups.

\section{DISCUSSION}

In this study, although the initial $\mathrm{pH}$ and lactic acid concentration were different between ATMR and LTMR, which preumably caused by the different properties between alfalfa hay and Leymus chinensis hay, both TMR silages obtained good fermentation quality after 56 days of ensiling as indicated by the high concentration of lactic acid, low $\mathrm{pH}$ and $\mathrm{NH}_{3}-\mathrm{N}$ concentration, and the absence of butyric acid. Such results may be attributed to the high epiphytic LAB populations $\left(10^{6} \mathrm{cfu} / \mathrm{g}\right.$ FM) and sufficient WSC concentrations (111 and $117 \mathrm{~g} / \mathrm{kg} \mathrm{DM}$ ) in the two types of TMR [24]. The differences in initial chemical and microbial compositions between ATMR and LTMR may lead to different variation trends in some fermentation qualities, microbial and chemical compositions parameters between two types of TMR silages during ensiling, which could be responsible for the significant interactions between days of ensiling and type of TMR observed in this study.

The efficient conservation of TMR silage with minimal losses during the storage period is important in providing ruminants with essential nutrients. In this study, the DM losses in both TMR silages during the ensiling period were small and within the acceptable range of $2 \%$ to $4 \%$ suggested by McDonald et al. [1]. WSC is the most critical in providing sufficient fermentable material for the production of high quality silages by LAB [2]. In this study, more than half of WSC were lost after $56 \mathrm{~d}$ of fermentation in both TMR silages, whereas the variations in WSC content could not explain the differences in acids production during ensiling. Similar results were obtained in our previous study on TMR silage formulated mainly with whole crop corn silage and other dry feeds [24], indicating that substances other than WSC are converted into acids during ensiling. In this study, besides the reduction in WSC content, loss of starch and hemicellulose was also observed in both TMR silages during ensiling. This finding is consistent with studies conducted by Melvin [5] and Yahaya et al. [6], which suggested that starch and hemicellulose could also serve as microbial substrates for the production of acids, thus contributing to the higher acids production than the loss in WSC content in both TMR silages.

It has been suggested that starch and hemicellulose can be degraded into some simple carbohydrates by plant and microbial enzymes under the acidic conditions [3,7]. As considering for the properties of TMR ingredients, the degradation of starch and hemicellulose during ensiling is probably the result of microbial enzyme mechanisms, since plant enzymes in soybean curd residue and other dry feedstuffs were inactivated during the high temperature processing or with extremely low moisture level. The detectable microbial amylase and hemicellulase

Table 6. Effects of pH on the amylase and hemicellulase activities of microbes isolated from ATMR and LTMR silages

\begin{tabular}{|c|c|c|c|c|c|c|c|c|c|}
\hline \multirow{2}{*}{ Group $^{1)}$} & \multirow{2}{*}{ Species } & \multicolumn{4}{|c|}{ Amylase activity $(\mathrm{U} / \mathrm{mL})^{2)}$} & \multicolumn{4}{|c|}{ Hemicellulase activity $(\mathrm{U} / \mathrm{mL})^{3)}$} \\
\hline & & pH4.0 & pH5.0 & pH6.0 & pH7.0 & $\mathrm{pH} 4.0$ & pH5.0 & $\mathrm{pH} 6.0$ & $\mathrm{pH} 7.0$ \\
\hline A1 & Bacillus amyloliquefaciens & $191 \pm 0.97$ & $255 \pm 4.35$ & $282 \pm 7.08$ & $307 \pm 6.29$ & $26.0 \pm 0.10$ & $56.4 \pm 0.48$ & $84.4 \pm 0.19$ & $65.6 \pm 2.61$ \\
\hline $\mathrm{A} 2$ & Bacillus cereus & $12.6 \pm 0.45$ & $24.8 \pm 0.97$ & $31.4 \pm 1.42$ & $19.6 \pm 0.18$ & - & - & - & - \\
\hline $\mathrm{L} 1$ & Bacillus flexus & nd & $6.77 \pm 0.18$ & $20.3 \pm 1.56$ & $13.5 \pm 0.24$ & - & - & - & - \\
\hline $\mathrm{A} 3 / \mathrm{L} 2$ & Bacillus licheniformis & $26.0 \pm 0.96$ & $82.8 \pm 2.89$ & $105 \pm 0.48$ & $77.0 \pm 6.08$ & $11.1 \pm 0.61$ & $19.5 \pm 1.31$ & $27.7 \pm 3.13$ & $17.8 \pm 0.61$ \\
\hline L3 & Bacillus pumilus & - & - & - & - & $16.4 \pm 0.40$ & $91.9 \pm 2.42$ & $249 \pm 4.74$ & $213 \pm 1.45$ \\
\hline A4 & Bacillus subtilis & $88.6 \pm 5.77$ & $260 \pm 0.96$ & $309 \pm 8.66$ & $225 \pm 4.43$ & $13.4 \pm 0.50$ & $22.0 \pm 1.49$ & $23.8 \pm 0.81$ & $16.1 \pm 0.72$ \\
\hline Ł4 & Paenibacillus xylanexedens & $7.34 \pm 0.41$ & $18.1 \pm 1.47$ & $19.4 \pm 1.93$ & $17.7 \pm 0.97$ & $5.9 \pm 0.68$ & $21.3 \pm 0.77$ & $30.7 \pm 0.82$ & $16.8 \pm 0.32$ \\
\hline A5/L5 & Enterococcus faecium & $31.0 \pm 1.01$ & $39.2 \pm 1.26$ & $27.6 \pm 1.37$ & $22.0 \pm 1.00$ & - & - & - & - \\
\hline
\end{tabular}

ATMR, total mixed ration prepared with alfalfa hay; LTMR, total mixed ration prepared with Leymus chinensis hay; nd, not detected.

Data are presented as means \pm standard deviation of three replicates.

1) Groups A1-A5 were isolated from ATMR (silages) and Groups L1-L5 were isolated from LTMR (silages).

2) One unit (U) of amylase activity was defined as the amount of enzyme required to release $1 \mu \mathrm{g}$ of maltose equivalents per minute under incubation at pH6.0 and $40^{\circ} \mathrm{C}$.

${ }^{3)}$ One unit $(U)$ of hemicellulase activity was defined as the amount of enzyme required to release $1 \mu \mathrm{g}$ of xylose equivalents per minute under incubation at $\mathrm{pH} 6.0$ and $40^{\circ} \mathrm{C}$. 
activities in both TMR silages also indicated the role of microbial enzymes in the degradation of starch and hemicellulose during ensiling. In this study, no molds were detected throughout the ensiling periods, and the number of yeasts decreased to undetectable level after $14 \mathrm{~d}$ of fermentation in both TMR silages. Moreover, no enzyme-producing yeasts species were detected among the yeasts isolated from our previous studies on TMR silages $[24,25]$. Thus, the role of aerobic bacteria and LAB in starch and hemicellulose degradation during ensiling in both TMR silages was mainly studied.

In this study, eight species that produced amylase or hemicellulase were isolated from ATMR, LTMR, and their silages. The majority of these species belonged to the genus Bacillus, one was P. xylanexedens, and another E. faecium. Many studies have reported that several species of Bacillus and Paenibacillus possess enzymes capable of degrading starch or hemicellulose [26-29], whereas common species of LAB available at ensiling lack hydrolytic activity toward those complex carbohydrates [2]. In this study, however, E. faecium was detected from both TMR silages, achieving good amylase production. Similar results were found by Shibata et al. [30] who isolated a novel amylolytic E. faecium from fermented raw rice in Philippines. Other efficient amylolytic Lactobacillus species such as L. plantarum and $L$. fermentum have also been reported from different tropical amylaceous fermented foods, further supporting the role of LAB in amylolysis and lactic acid production [31].

In ATMR and its silages, five amylolytic species, B. amyloliquefaciens, B. cereus, B. licheniformis, B. subtilis, and E. faecium, were isolated during ensiling, whereas other two amylolytic species, B. flexus and P. xylanexedens, in addition to B. licheniformis and E. faecium, were isolated from LTMR and its silages. It is well known that Bacillus and Paenibacillus species are endospore-forming microbes that can enter dormancy as spores to survive harsh environmental conditions [32]. In this study, six amylase-producing species belonging to the genera Bacillus and Paenibacillus were detected even at the later stage of fermentation, when low $\mathrm{pH}$ or anaerobic conditions are normally not suitable for their growth. Their presence may be ascribed to the spores that existed in silages could return to a vegetative state rapidly during the screening process as the selection mediums provided favorable conditions for their germination [33]. In view of the microbial and enzymatic properties of the detected amylolytic species, the main amylase-producing microbes during the early stage of fermentation were represented by four Bacillus species (B. amyloliquefaciens, B. cereus, B. licheniformis, and B. subtilis) in ATMR silage and B. flexus, $B$. licheniformis, and P. xylanexedens in LTMR silages, as these species grew well and the amylase produced by these species presented good activities in the $\mathrm{pH}$ range of 5.0 to 7.0 in this study. However, the role of these species in starch hydrolysis seemed to be disappeared at the later stage of fermentation since low $\mathrm{pH}$ or anaerobic conditions inhibited their growth and induced their conversion to metabolically dormant spores [33]. Meanwhile, the detection of amylolytic E. faecium after 7 $\mathrm{d}$ of fermentation indicated that it also plays a part in starch hydrolysis, especially at the later stage of fermentation, because this facultative anaerobe could grow well and displayed good amylase activity even at $\mathrm{pH}$ below 4.5. The results presented herein are inconsistent with a previous study, which reported little growth of amylolytic E. faecium at $\mathrm{pH}$ below 5.5 [30]. In contrast, a study conducted by $\mathrm{Ni}$ et al. [34] reported that $E$. faecium isolated from forage paddy rice silage grew well within the $\mathrm{pH}$ range of 4.0 to 7.0 . With regard to the amylase activity of each detected species, the level of enzyme activity varied among the species. In this study, B. amyloliquefaciens and B. subtilis presented higher amylase activity compared to other isolated amylolytic species. Similar results were reported by Hussain et al. [29] who indicated that Bacillus species such as B. amyloliquefaciens, B. licheniformis, and B. subtilis are generally preferred for the production of amylase because they appear to be very productive. Thus, the detection of B. amyloliquefaciens and B. subtilis with high amylase activity in ATMR and its silages might account for the higher microbial amylase activity and greater starch hydrolysis observed in ATMR silages compared to that in LTMR silages during the early stage of ensiling. Moreover, the amylase produced by most of the detected amylolytic species in this study exhibited maximum activity at $\mathrm{pH}$ 6.0, except for B. amyloliquefaciens and E. faecium, with the optimum $\mathrm{pH}$ of 7.0 and 5.0, respectively. The enzyme activity of the detected amylolytic species decreased as the $\mathrm{pH}$ level decreased below the optimal value. Therefore, the decrease in microbial amylase activity in both TMR silages during fermentation may be the result of the succession of dominant amylase-producing microbes from Bacillus and Paenibacillus species to E. faecium accompanied with the change in $\mathrm{pH}$ during ensiling.

Among the hemicellulolytic microbes, B. amyloliquefaciens, B. licheniformis, and B. subtilis were isolated from ATMR and its silages, and B. licheniformis, B. pumilus and P. xylanexedens were the main hemicellulase-producing microbes in LTMR and its silages. However, these species seemed to play little role in hemicellulose degradation at the later stage of fermentation in both TMR silages since the microbial hemicellulase activity declined to undetectable level at day 14 post-ensiling, which might be attributable to their transformation to metabolically dormant spores triggered by low $\mathrm{pH}$ and anaerobic conditions [33]. Meanwhile, hemicellulolytic LAB were not isolated during ensiling from both TMR silages. However, losses of hemicellulose did not cease after $14 \mathrm{~d}$ of fermentation, indicating that other factors may be involved in the hemicellulose degradation during ensiling. Research on grasses has demonstrated hemicellulose to be degraded by both plant enzymes and the hydrolysis of organic acids produced during fermentation [7]. According to their study, considerable hydrolysis of hemicellulose may oc- 
cur in low $\mathrm{pH}$ silages stored for a long period of time. Thus, in this study, although the hemicellulase activity was inactive after $14 \mathrm{~d}$ of fermentation, the high concentrations of lactic and acetic acids produced during ensiling could lead to the continued loss of hemicellulose in both TMR silages. Moreover, a higher loss of hemicellulose in LTMR silages compared to that in ATMR silages observed in this study is presumably due to the role of high hemicellulase-producing $B$. pumilus isolated in LTMR and its silages as well as the differences in the structure of cell wall components between alfalfa and Leymus chinensis, since the grasses have more acid-susceptible arabinoxylans compared to legumes [35]. The degradation of hemicellulose caused by both microbial enzymes and acid hydrolysis might contribute to the decrement in aNDF contents in both TMR silages. Similarly, a decrease in ADF contents was observed in both TMR silages. Previous study demonstrated that the cellulose could also be degraded by acids produced during ensiling [36]. Therefore, the decrease in ADF contents in this study was probably due to the loss of cellulose during ensiling, and further studies on the cellulose degradation during ensiling should be performed.

\section{CONCLUSION}

Microbial amylase plays a role in starch hydrolysis during ensiling in both TMR silages. Four Bacillus species, B. amyloliquefaciens, $B$. cereus, B. licheniformis, and B. subtilis, and three species including $B$. flexus, B. licheniformis, and P. xylanexedens are the main amylase-producing microbes during the early stage of ensiling in ATMR and LTMR silages, respectively. E. faecium is closely associated with starch hydrolysis at the later stage of fermentation in both TMR silages. Microbial hemicellulase participates in the hemicellulose degradation only at the early stage of ensiling. The main hemicellulase-producing microbes include B. amyloliquefaciens, B. licheniformis, and B. subtilis in ATMR silages and B. licheniformis, B. pumilus, and P. xylanexedens in LTMR silages. To clarify the mechanisms associated with hemicellulose degradation in TMR silage during the entire fermentation process, future studies on the roles of acids in hemicellulose degradation in TMR silages during ensiling should be performed.

\section{CONFLICT OF INTEREST}

We certify that there is no conflict of interest with any financial organization regarding the material discussed in the manuscript.

\section{ACKNOWLEDGMENTS}

This work was financially supported by the National Natural Science Foundation of China (31172240), the International S\&T cooperation program of China (2015DFG32360), and the Chinese Universities Scientific Fund (2013YJ007).

\section{REFERENCES}

1.McDonald P, Henderson AR, Heron SJE. The Biochemistry of Silage. 2nd ed. Welton, Lincoln: Chalcombe Publications; 1991.

2.Rooke JA, Hatfield RD. Biochemistry of ensiling. In: Buxton DR, Muck RE, Harrison HJ, editors. Silage Science and Technology. Madison, WI: American Society of Agronomy; 2003. p. 95-139.

3.Muck RE. 1990. Dry matter level effects on alfalfa silage quality. II. Fermentation products and starch hydrolysis. Trans Am Soc Agric Eng 1990;33:373-81.

4.Chen L, Guo G, Yu CQ, Zhang J, Shimojo M, Shao T. The effects of replacement of whole-plant corn with oat and common vetch on the fermentation quality, chemical composition and aerobic stability of total mixed ration silage in Tibet. Anim Sci J 2015;86: 69-76.

5.Melvin JF. Variations in the carbohydrate content of lucerne and the effect on ensilage. Aust J Agric Res 1965;16:951-9.

6.Yahaya MS, Kimura A, Harai J, et al. Effect of length of ensiling on silo degradation and digestibility of structural carbohydrates of lucerne and orchardgrass. Anim Feed Sci Technol 2001;92: 141-8.

7.Dewar WA, McDonald P, Whittenbury R. The hydrolysis of grass hemicelluloses during ensilage. J Sci Food Agric 1963;14:411-7.

8.Xu CC, Cai YM, Moriya N, Ogawa M. Nutritive value for ruminants of green tea grounds as a replacement of brewers' grains in totally mixed ration silage. Anim Feed Sci Technol 2007;138:228-38.

9.Hu XD, Hao W, Wang HL, Ning TT, Zheng ML, Xu CC. Fermentation characteristics and lactic acid bacteria succession of total mixed ration silages formulated with peach pomace. AsianAustralas. J Anim Sci 2015;28:502-10.

10. AOAC International. Official methods of analysis. 15th ed. Arlington, VA: Association of Official Analytical Chemists; 1990.

11. Van Soest PJ, Robertson JB, Lewis BA. Mehtods for dietary fiber, neutral detergent fiber, and non-starch polysaccharides in relation to animal nutrition. J Dairy Sci 1991;74:3583-97.

12. Owens VN, Albrecht KA, Muck RE, Duke SH. Protein degradation and fermentation characteristics of red clover and alfalfa silage harvested with varying levels of total nonstrucural carbohydrates. Crop Sci 1999;39:1873-80.

13. Broderick GA, Kang JH. Automated simultaneous determination of ammonia and total amino acid in ruminal fluid and in vitro media. J Dairy Sci 1980;63:64-75.

14. Rosés RP, Guerra NP. Optimization of amylase production by Aspergillus niger in solid-state fermentation using sugarcane bagasse as solid support material. World J Microb Biot 2009;25: 1929-39.

15. Miller GL. Use of dinitrosalicylic acid reagent for determination of reducing sugar. Anal Chem 1959;31:426-8.

16. Rickard PAD, Laughlin TA. Detection and assay of xylanolytic enzymes in a Cellulomonas isolate. Biotechnol Lett 1980;2:363- 
8.

17. Lee HS, Gilliland SE, Carter S. Amylolytic cultures of Lactobacillus acidophilus: Potential probiotics to improve dietary starch utilization. J Food Sci 2001;66:338-44.

18. Cai YM, Kumai S, Ogawa M, Benno Y, Nakase T. Characterization and identification of Pediococcus Species isolated from forage crops and their application for silage preparation. Appl Environ Microbiol 1999;65:2901-6.

19. Thompson JD, Higgins DG, Gibson TJ. CLUSTAL W: improving the sensitivity of progressive multiple sequence alignment through sequence weighting, position-specific gap penalties and weight matrix choice. Nucleic Acids Res 1994;22:4673-80.

20. Kimura M. A simple method for estimating evolutinary rates of base substitutions through comparative studies of nucleotide sequences. J Mol Evol 1980;16:111-20.

21. Saitou N, Nei M. The neighbor-joining method: a new method for reconstructing phylogenetic trees. Mol Biol Evol 1987;4:40625.

22. Tamura K, Stecher G, Peterson D, Filipski A, Kumar S. MEGA6: molecular evolutionary genetics analysis version 6.0. Mol Biol Evol 2013;30:2725-9.

23. Liu QH, Shao T, Zhang JG. Determination of aerobic deterioration of corn stalk silage caused by aerobic bacteria. Anim Feed Sci Technol 2013;183:124-31.

24. Wang HL, Ning TT, Hao W, Zheng ML, Xu CC. Dynamics associated with prolonged ensiling and aerobic deterioration of total mixed ration silage containing whole crop corn. Asian-Australas J Anim Sci 2016;29:62-72.

25. Hao W, Wang HL, Ning TT, Yang FY, Xu CC. Aerobic stability and effects of yeasts during deterioration of non-fermented and fermented total mixed ration with different moisture levels. Asian-Australas J Anim Sci 2015;28:816-26.

26. Breccia JD, Sineriz F, Baigori MD, Castro GR, Hatti-Kaul R. Purification and characterization of a thermostable xylanase from Bacillus amyloliquefaciens. Enzyme Microb Tech 1998;22:
42-9.

27. Nelson DM, Glawe AJ, Labeda DP, Cann IKO, Mackie RI. Paenibacillus tundrae sp. nov. and Paenibacillus xylanexedens sp. nov., psychrotolerant, xylan-degrading bacteria from Alaskan tundra. Int J Syst Evol Microbiol 2009;59:1708-14.

28. Ikram-Ul-Haq, Hameed U, Mahmood Z, Javed MM. Solid state fermentation for the production of a-amylase by Paenibacillus amylolyticus. Pak J Bot 2012;44:341-6.

29. Hussain I, Siddique F, Mahmood MS, Ahmed SI. A review of the microbiological aspect of alpha-amylase production. Int J Agric Biol 2013;15:1029-34.

30. Shibata K, Flores DM, Kobayashi G, Sonomoto K. Direct L-lactic acid fermentation with sago starch by a novel amylolytic lactic acid bacterium, Enterococcus faecium. Enzyme Microb Tech 2007; 41:149-55.

31. Reddy G, Altaf M, Naveena BJ, Venkateshwar M, Kumar EV. Amylolytic bacterial lactic acid fermentation - A review. Biotechnol Adv 2008;26:22-34.

32. Pahlow G, Muck RE, Driehuis F, Elferink SO, Spoelstra SF. Microbiology of ensiling. In: Buxton DR, Muck RE, Harrison HJ, editors. Silage Science and Technology. Madison, WI: American Society of Agronomy; 2003. p. 31-93.

33. Liu SL, Wu WJ, Yung PT. Effect of sonic stimulation on Bacillus endospore germination. FEMS Microbiol Lett 2016;363:1-7.

34. Ni KK, Wang YP, Li DX, Cai YM, Pang HL. Characterization, identification and application of lactic acid bacteria isolated from forage paddy rice silage. PlOS ONE 2015;10:e0121967.

35. Morrison IM. Influence of some chemical and biological additives on the fibre fraction of lucerne on ensilage in laboratory silos. J Agric Sci 1988;111:35-9.

36. Yahaya MS, Kawai M, Takahashi J, Matsuoka S. The effects of different moisture content and ensiling time on silo degradation of structural carbohydrate of orchadrass. Asian-Australas J Anim Sci 2002;15:213-7. 